\title{
Hypertrophic scarring in cleft lip repair: a comparison of incidence among ethnic groups
}

This article was published in the following Dove Press journal:

Clinical Epidemiology

24 July 2012

Number of times this article has been viewed

\author{
Ali M Soltani \\ Cameron S Francis \\ Arash Motamed \\ Ashley L Karatsonyi \\ Jeffrey A Hammoudeh \\ Pedro A Sanchez-Lara \\ John F Reinisch \\ Mark M Urata \\ Division of Plastic and Maxillofacia \\ Surgery at Children's Hospital Los \\ Angeles, CA, USA; The Division of \\ Plastic and Reconstructive Surgery \\ at the Keck School of Medicine \\ of the University of Southern \\ California, Los Angeles, CA, USA
}

Correspondence: Mark M Urata 4650 Sunset Blvd, MS \#96,

Los Angeles, CA 90027, USA

Tel 323 36I-2I54

Fax 323 36I-4089

Email murata@chla.usc.edu
Background: Although hypertrophic scar (HTS) formation following cleft lip repair is relatively common, published rates vary widely, from $1 \%$ to nearly $50 \%$. The risk factors associated with HTS formation in cleft patients are not well characterized. The primary aim of this retrospective study of 180 cleft lip repairs is to evaluate the frequency of postoperative HTS among various ethnic groups following cleft lip repair.

Methods: A retrospective chart view of patients undergoing primary cleft lip repair over a 16-year period (1990-2005) by the senior surgeon was performed. The primary outcome was the presence of HTS at 1 year postoperatively. Bivariate analysis and multivariable logistic regression were used to evaluate potential risk factors for HTS, including ethnicity, type and laterality of cleft, and gender.

Results: One hundred and eighty patients who underwent cleft lip repair were included in the study. The overall rate of postoperative HTS formation was $25 \%$. Ethnicity alone was found to be an independent predictor of HTS formation. Caucasian patients had the lowest rate of HTS formation (11.8\%) and were used as the reference group. HTS rates were significantly higher in the other ethnicities, $32.2 \%$ in Hispanic patients (odds ratio [OR]: 3.51 ; 95\% confidence interval [CI]: 1.53-8.85), and 36.3\% for Asian patients (OR 4.27; 95\% CI: 1.36-13.70). Sex, cleft type, and cleft laterality were not associated with increased rates of HTS.

Conclusions: Differences in ethnic makeup of respective patient populations may be a major factor influencing the wide variability of reported HTS rates. Consideration should be given to potential prophylactic treatments for HTS in susceptible ethnic populations.

Keywords: cleft lip, hypertrophic scarring, ethnicity, epidemiology

\section{Introduction}

Cleft lip (with or without cleft palate) is the most commonly reported congenital anomaly requiring surgery, occurring at a rate of 79.1 per 100,000 live births. ${ }^{1}$ In California, the incidence of cleft lip (with or without cleft palates) is 74.1 per 100,000 live births. ${ }^{2}$ This congenital malformation is referred to pediatric plastic surgeons and requires early repair for functional, esthetic, and psychosocial reasons.

Hypertrophic scar (HTS) formation is a postoperative complication of cleft lip repair and may often require surgical revision. The pathogenesis of hypertrophic scars is not clear and much of our understanding is from anecdotal, clinical experience. Normal wound healing progresses through well recognized and refined phases. The initial period of hyperemia represents revascularization. This is followed by collagen realignment and wound maturation. In a subset of patients, the normal physiologic scar maturation process becomes unregulated. The reorganization of collagen may lead 
to aberrant growth within the margins, which may present as elevated, pruritic, and sometimes painful scar that can be classified as hypertrophic.

Hypertrophic scarring generally occurs within 3-6 months following the initial injury. Once formed the scar may remain static in size or begin to regress. ${ }^{3,4}$ This regression in the cleft lip patient can lead to a shortened lip on the affected side. HTS remains confined within the site of the original wound, increasing in size primarily through growth in the perpendicular plane rather than lateral invasion. ${ }^{5}$

In the perioral region, HTS formation can result in esthetically deforming scars that may lead to secondary cleft lip revision. Aberrant scar formation following cleft lip repair is associated with lip asymmetry and nasal stenosis. Rates of HTS formation following cleft lip repair have rarely been reported and those that have vary widely, from $8 \%$ to $47 \%$ according to various authors. ${ }^{6-9}$ In addition, there appears to be no data addressing patient and demographic factors associated with subsequent HTS formation. Our experience at the Children's Hospital Los Angeles suggests a higher rate of hypertrophic scarring in Hispanic and Asian populations. To our knowledge, there are no published studies that compare the rate of hypertrophic scarring among various ethnic groups after cleft lip repair. The aim of this study is to determine differences that may exist between ethnicities with respect to the formation of HTS following primary cleft lip repair.

\section{Materials and methods}

After obtaining institutional review board approval, we conducted a retrospective chart review of all patients who underwent primary cleft lip repair by a single surgeon (JF Reinisch) at Children's Hospital Los Angeles from June 1990 to June 2005. For all patients, cleft lip repair was performed using a standard rotational-advancement technique. Skin closure was accomplished with multiple interrupted dermal 6-0 polydioxanone sutures followed by either Dermabond (Ethicon, Inc, Somerville, NJ) or Steri-Strips (3M Company, St Paul, MN).

Postoperatively, all patients received long-term longitudinal follow-up through enrollment in the CHLA cleft team. Each patient's admission sheet was reviewed to identify the ethnicity of the patient, as stated by the patients' parents/ guardians. Available choices were Hispanic, Caucasian, Asian, African American, and other.

Data were abstracted from progress notes written by the senior author, and based on digital photographic records. Each chart was reviewed for documentation of HTS at 1-year post-primary cleft lip repair (+/-3 months).
Specifically, patients were screened for HTS based on any references in the follow-up clinic notes to scars that were thick, reddened, irregular, or hypertrophic. For each patient with positive findings on the chart review, the diagnosis of HTS was confirmed using photographic records by the study team if the scar appeared to be wider than $3 \mathrm{~mm}$ with a pink or red color.

Two examples of patients with HTS are shown; Figure 1 demonstrates a child with a right unilateral cleft lip HTS, and in Figure 2 an HTS developed on the right side in a patient with bilateral cleft lip repair. Further, the patient's gender, cleft classification, and type of cleft (ie, unilateral vs bilateral and incomplete vs complete) were recorded. Patients with disorders or conditions that could impair wound healing such as Ehlers-Danlos or Marfan syndromes were excluded. A history of previous hypertrophic or keloid scarring was also considered an exclusion criterion; however, this applied to no patients in our study. Due to small sample size (1), African American patients were excluded from the statistical analysis as were patients with ethnicity identified as other.

Data were analyzed using the software JMP (v 9; SAS Institute Inc, Cary, NC). Bivariate statistics (Fisher's exact tests) were used to analyze HTS rates in patients stratified by risk factors including ethnicity, cleft laterality (unilateral or bilateral), gender, and cleft type (incomplete or complete). To identify independent predictors of HTS formation, multivariable logistic regression was performed using the same risk factors from the stratified analysis as independent variables. HTS was used as the dependent variable for the regression model. A value of $P<0.05$ was considered statistically significant.

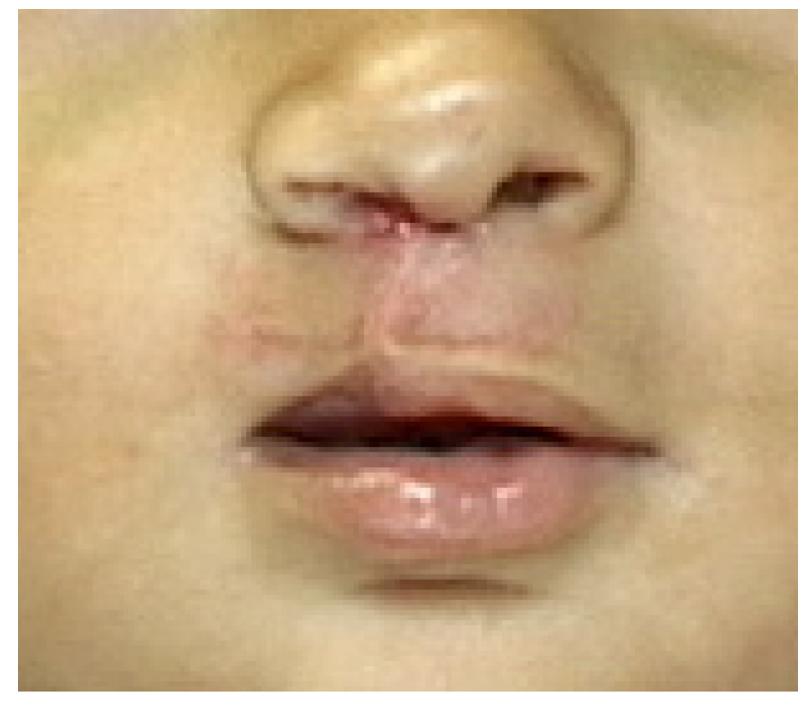

Figure I Right unilateral cleft lip hypertrophic scar. 


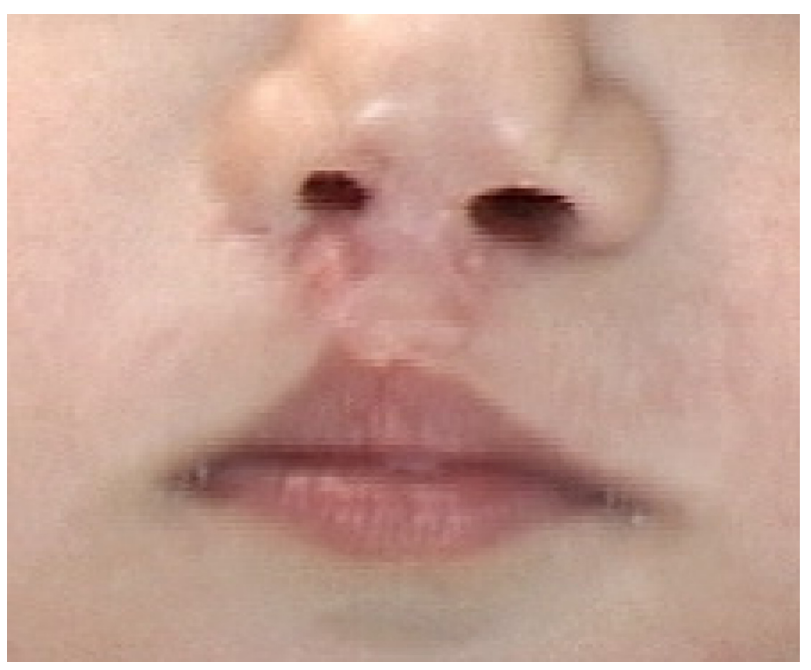

Figure 2 Bilateral cleft lip, hypertrophic scar on right side.

\section{Results}

The charts of 186 patients who underwent primary cleft lip repair were reviewed. Of these, 180 met the inclusion criteria. The remaining six were excluded from the study because of previously mentioned exclusion criteria or incomplete information regarding the patients' scars, race, or follow-up. The average age was 4.3 months at the time of cleft lip repair, which was similar between ethnic populations. The overall presence of cleft lip hypertrophic scarring was noted in $25 \%$ of patients with the remaining $75 \%$ displaying normal wound healing. Bivariate analysis of HTS rates stratified by risk factor demonstrated a statistically significant difference in the rate of hypertrophic scarring among the three ethnicities (Table 1). The lowest rate of HTS formation was observed in Caucasians (11.8\%) compared with Hispanics (32.2\%) and Asians (36.3\%). Multivariable regression analysis revealed ethnicity to be the only independent predictor of HTS formation among the potential risk factors considered, with elevated odds ratios (ORs) observed in Asian (OR: 4.27; 95\% confidence interval $[\mathrm{CI}]: 1.36-13.70 ; P=0.014)$ and Hispanic (OR: 3.51; 95\% CI: $1.53-8.85 ; P=0.003$ ) patients, compared with Caucasians (Table 2).

\section{Discussion}

Determining the accurate frequency of hypertrophic scarring presents numerous challenges when attempting to compare published rates among various ethnicities. There are many confounding factors such as the age of the patient, nature and location of the wound, time at which the wound is evaluated, and subjectivity on the surgeon's part associated with
Table I Bivariate statistics analyzing HTS rates stratified by risk factors

\begin{tabular}{llll}
\hline Risk factor & No & HTS rate (\%) & P-value \\
\hline $\begin{array}{llll}\text { Sex } \\
\text { Female }\end{array}$ & 67 & 25.4 & $>0.999$ \\
$\quad$ Male & 113 & 24.8 & Reference \\
$\begin{array}{lll}\text { Ethnicity } \\
\text { Asian }\end{array}$ & 22 & 36.3 & $0.02 I^{*}$ \\
Hispanic & 90 & 32.2 & $0.003^{*}$ \\
$\begin{array}{l}\text { Caucasian } \\
\text { Cleft characteristics }\end{array}$ & 68 & 11.8 & Reference \\
Bilateral & 35 & 28.6 & 0.664 \\
Unilateral & 145 & 24.1 & Reference \\
Complete & 103 & 28.1 & 0.389 \\
Incomplete & 77 & 20.7 & Reference \\
\hline
\end{tabular}

Note: *Indicates statistical significance at the level of 0.05 .

the qualitative assessment of the scar. This paper mitigates many of these variables by evaluating the data on hypertrophic scarring following cleft lip repair for various ethnicities within our institution and relying on the assessment of our senior plastic surgeon with extensive clinical experience in this field. Further, these assessments were confirmed through patient photographic records.

Our HTS rate in Caucasians is comparable to published literature from the UK on cleft lip repair, $12 \%-18 \%{ }^{6}$ Similarly, our HTS rate in Asians is comparable to rates published by Japanese surgeons, up to $27 \% .^{8,9}$ The majority of published reports have investigated the formation of HTS as a complication of thermal injuries, which appear to have a higher frequency than those associated with surgical wounds. ${ }^{10}$ Additionally, most studied subjects have been adults and there is evidence that the intensity of scar formation differs with age. ${ }^{3}$ Nevertheless, the reported incidence of HTS in adults ranges from $37 \%$ to $68 \%$ for surgical wounds

Table 2 Multivariable logistic regression to identify independent predictors of HTS post-cleft lip repair

\begin{tabular}{|c|c|c|}
\hline Risk factor & Odds ratio $(95 \% \mathrm{CI})$ & $P$-value \\
\hline \multicolumn{3}{|l|}{ Sex } \\
\hline Female & $1.05(0.51-2.19)$ & 0.893 \\
\hline Male & Reference & - \\
\hline \multicolumn{3}{|l|}{ Ethnicity } \\
\hline Asian & $4.27(1.36-13.70)$ & $0.014 *$ \\
\hline Hispanic & $3.51(1.53-8.85)$ & $0.003 *$ \\
\hline Caucasian & Reference & - \\
\hline \multicolumn{3}{|c|}{ Cleft characteristics } \\
\hline Bilateral & $1.28(0.52-2.98)$ & 0.572 \\
\hline Unilateral & Reference & - \\
\hline Complete & $1.27(0.63-2.62)$ & 0.506 \\
\hline Incomplete & Reference & - \\
\hline
\end{tabular}

Note: *Indicates statistical significance at the level of 0.05 .

Abbreviations: $\mathrm{Cl}$, confidence intervals; HTS, hypertrophic scar. 
and $33 \%$ to $91 \%$ for thermal injuries. ${ }^{6,11-13}$ In burn patients under the age of 5 years, hypertrophic scarring incidence ranges from $30 \%$ to $65 \%,{ }^{14,15}$ while in children between 6 and 15 years of age, the incidence is approximately $50 \% .^{13}$

We noted a high rate of HTS in our pigmented pediatric population undergoing primary cleft lip surgery. In comparison, the adult, Chinese population is reported to have an incidence of $74.7 \%{ }^{16} 1$ month after orthopedic surgery and $44.6 \%{ }^{6}$ following linear orthopedic procedures. While literature on the Hispanic population is lacking, the incidence of hypertrophic scarring for the fair-skinned, Northern European population has been stated to be up to $37 \%$ following median sternotomy, ${ }^{10}$ however these areas (chest, extremities) are under tension and are subject to poorer scarring. Lastly, one study on thermal injuries has reported that African Americans fare worse than Caucasians in hypertrophic scar development. ${ }^{17}$

In determining the rate of hypertrophic scarring among various races, our study was limited by the lack of African American subjects (one patient, excluded from analysis), which in part may be a reflection of Los Angeles County's demographics where $47.3 \%$ are Hispanic, 29.2\% are White, $13.1 \%$ are Asian, and 9.6\% are African American. ${ }^{18}$ Moreover, the incidence of orofacial clefts varies with race such that Asians have the highest incidence, followed by Caucasians, Hispanics, and African Americans. ${ }^{17,19-22}$ Our data agrees with the literature and the anecdotal experience that darker pigmented individuals have a higher frequency of hypertrophic scarring. Additionally, a study that had investigated HTS incidence following thermal injuries had reported the incidence to be $75 \%$ in non-Caucasians patients and $60 \%$ in Caucasian patients. ${ }^{23}$

This study did not show a correlation between gender and HTS. This lack of association is consistent with studies on Chinese and darker pigmented individuals which did not show a significant difference in HTS between female and male groups. ${ }^{15,24}$ Furthermore, we found no statistical association between hypertrophic scarring incidences in unilateral vs bilateral and incomplete vs complete cleft lips. This study, however, does clearly demonstrate a higher frequency of hypertrophic scarring in the non-Caucasian group, regardless of gender, laterality, and type of cleft.

Hypertrophic cleft lip scars can cause emotional and mental distress along with functional and esthetic complications leading to frequent secondary cleft lip revisions. These cleft lip revisions can cause increased parental and patient stress, added anesthetic and surgical risks, and increased parental and societal costs.
If a patient does develop HTS following cleft lip repair, there are various treatment modalities available. If erythema or pruritis is the prevailing complaint, intralesional steroids may be injected. Further, silicone taping has been shown to flatten and improve the appearance of the hypertrophic scar postoperatively. There are few proven techniques that prevent hypertrophic scarring, but following meticulous surgical technique with precise alignment of the skin can possibly reduce this risk. Ultimately, many patients with hypertrophic scarring or contracture post cleft lip repair may require a scar revision or z-plasty for scar camouflage. However, even with this surgical treatment, it may still recur.

Our study illustrates that in the pediatric population, 1 year following cleft lip repair, Asian and Hispanic populations have three times the rate of hypertrophic scarring than do Caucasians. Further studies can enhance our comprehension of the potential genetic, environmental, and social reasons behind these results. These data lend credence to our initial clinical impression and provides incentive to further explore potential prophylactic treatments for hypertrophic scars in susceptible populations.

\section{Disclosure}

The authors report no conflicts of interest in this work.

\section{References}

1. Martin JA, Hamilton BE, Sutton PD, et al; Centers for Disease Control and Prevention National Center for Health Statistics National Vital Statistics System. Births: final data for 2005. Natl Vital Stat Rep. 2007;56(6):1-103.

2. Shaw GM, Croen LA, Curry CJ. Isolated oral cleft malformations: association with maternal and infant characteristics in a California population. Teratology. 1991;43(3):225-228.

3. Muir IF. On the nature of keloid and hypertrophic scars. Br J Plast Surg. 1990;43(1):61-69.

4. Zurada JM, Kriegel D, Davis IC. Topical treatments for hypertrophic scars. J Am Acad Dermatol. 2006;55(6):1024-1031.

5. Peacock EE Jr, Madden JW, Trier WC. Biologic basis for the treatment of keloids and hypertrophic scars. South Med J. 1970;63(7):755-760.

6. Wilson AD, Mercer N. Dermabond tissue adhesive versus Steri-Strips in unilateral cleft lip repair: an audit of infection and hypertrophic scar rates. Cleft Palate Craniofac J. 2008;45(6):614-619.

7. Holtmann B, Wray RC. A randomized comparison of triangular and rotiation-advancement unilateral cleft lip repairs. Plast Reconstr Surg. 1983;71(2):172-179.

8. Onizuka T, Ichinose M, Hosaka Y, Usui Y, Jinnai T. The contour lines of the upper lip and a revised method of cleft lip repair. Ann Plast Surg. 1991;27(3):238-252.

9. Ohne H. Keloid formation at the primary repair of cleft lip patient. Showa Uni J Med Sci. 1986;46:249.

10. Lewis WH, Sun KK. Hypertrophic scar: a genetic hypothesis. Burns. 1990;16(3):176-178.

11. Elliot D, Cory-Pearce R, Rees GM. The behaviour of presternal scars in a fair-skinned population. Ann R Coll Surg Engl. 1985;67(4):238-240.

12. Deitch EA, Wheelahan TM, Rose MP, Clothier J, Cotter J. Hypertrophic burn scars: analysis of variables. J Trauma. 1983;23(10):895-898. 
13. Niessen FB, Spauwen PH, Robinson PH, Fidler V, Kon M. The use of silicone occlusive sheeting (Sil-K) and silicone occlusive gel (Epiderm) in the prevention of hypertrophic scar formation. Plast Reconstr Surg. 1998;102(6):1962-1972.

14. Dedovic Z, Koupilová I, Brychta P. Time trends in incidence of hypertrophic scarring in children treated for burns. Acta Chir Plast. 1999;41(3):87-90.

15. Spurr ED, Shakespeare PG. Incidence of hypertrophic scarring in burninjured children. Burns. 1990;16(3):179-181.

16. Li-Tsang CW, Lau JC, Chan CC. Prevalence of hypertrophic scar formation and its characteristics among the Chinese population. Burns. 2005;31(5):610-616.

17. McDonald WS, Deitch EA. Hypertrophic skin grafts in burned patients: a prospective analysis of variables. J Trauma. 1987;27(2):147-150.

18. 2006 US Census Bureau State and County QuickFacts. Available from: http://quickfacts.census.gov/qfd/states/06/06037.html. Accessed November 5, 2008.
19. Menegotto BG, Salzano FM. Epidemiology of oral clefts in a large South American sample. Cleft Palate Craniofac J. 1991;28(4):373-376; discussion 376-377.

20. Leck I. The geographical distribution of neural tube defects and oral clefts. Br Med Bull. 1984;40(4):390-395.

21. Tolarova M. A study of the incidence, sex-ratio, laterality and clinical severity in 3,660 probands with facial clefts in Czechoslovakia. Acta Chir Plast. 1987;29(2):77-87.

22. Croen LA, Shaw GM, Wasserman CR, Tolarová MM. Racial and ethnic variations in the prevalence of orofacial clefts in California, 1983-1992. Am J Med Genet. 1998;79(1):42-47.

23. Bombaro KM, Engrav LH, Carrougher GJ, et al. What is the prevalence of hypertrophic scarring following burns? Burns. 2003;29(4):299-302.

24. Munro KJ. Treatment of hypertrophic and keloid scars. J Wound Care. $1995 ; 4(5): 243-245$
Clinical Epidemiology

\section{Publish your work in this journal}

Clinical Epidemiology is an international, peer-reviewed, open access journal focusing on disease and drug epidemiology, identification of risk factors and screening procedures to develop optimal preventative initiatives and programs. Specific topics include: diagnosis, prognosis, treatment, screening, prevention, risk factor modification, systematic

Submit your manuscript here: http://www.dovepress.com/clinical-epidemiology-journa

\section{Dovepress}

reviews, risk \& safety of medical interventions, epidemiology \& biostatical methods, evaluation of guidelines, translational medicine, health policies \& economic evaluations. The manuscript management system is completely online and includes a very quick and fair peer-review system, which is all easy to use. 